\title{
ESTIMATIVAS DE VARIÂNCIA GENÉTICAADITIVA EM POPULAÇÕES SELECIONADAS E NÃO-SELECIONADAS VIA SIMULAÇÃO MONTE CARLO UTILIZANDO O SOFTWARE R
}

\author{
Additive genetic variance estimates in selected and unselected populations \\ via Monte Carlo simulation using the $\mathbf{R}$ software
}

\author{
Ricardo Luis dos Reis ${ }^{1}$, Joel Augusto Muniz ${ }^{2}$, Fabyano Fonseca e Silva ${ }^{3}$, Luiz Henrique de Aquino ${ }^{4}$
}

\begin{abstract}
RESUMO
Para disponibilizar um sistema de fornecimento de dados que objetivando-se subsidiar pesquisas de Melhoramento Genético Animal direcionadas à comparação de metodologias de avaliação genética, foi avaliado o comportamento da variância genética aditiva de populações selecionadas e não selecionadas, por seis gerações sucessivas, via simulação Monte Carlo. Por meio de um modelo genético aditivo, foram simuladas populações de 40 animais (20 machos e 20 fêmeas), sob seleção e acasalamento aleatório. Da geração zero até a quinta geração notou-se na população selecionada uma redução de $44,4 \%$ na variância genética aditiva, devido a um aumento de 11,58\% no coeficiente de endogamia. Na população não selecionada a redução da variância genética aditiva foi menor $(27,46 \%)$ em relação à população selecionada, também devido a aumento de 10,26\% no coeficiente de endogamia.
\end{abstract}

Termos para indexação: Modelo genético aditivo, simulação Monte Carlo, variância genética aditiva, software R.

\section{ABSTRACT}

The additive genetic variance in selected and unselected populations was evaluated in six successive generations via Monte Carlo simulation. The aim was to build a data system to help researches compare genetic evaluation methodologies in Animal Breeding. By means of an additive genetic model, populations of 40 individuals (20 males and 20 females) were simulated, under selected and random mating system. From the generation zero until the fifth generation, the selected population showed reduction of $44.4 \%$ in additive genetic variance due to an increase of $11.58 \%$ in inbreeding coefficient. In the unselected population the reduction in additive genetic variance was lower $(27.46 \%)$ in relation to the selected population, due to the increasing of $10.26 \%$ in inbreeding coefficient.

Index terms: Additive genetic model, Monte Carlo Simulation, additive genetic variance, $\mathrm{R}$ software.

(Recebido em 31 de janeiro de 2006 e aprovado em 8 de maio de 2008)

\section{INTRODUÇÃo}

A maioria dos dados disponíveis para os pesquisadores de Melhoramento Genético Animal não apresenta os requerimentos de amostragem aleatória, ou seja, os dados são provenientes de rebanhos que estão sob seleção. De modo geral, nas análises destes dados os efeitos da seleção são ignorados, o que pode resultar em estimativas e predições viesadas na avaliação genética dos animais.

Segundo Fairfull \& Muir (1997), os métodos de avaliação genética animal seguem a metodologia dos modelos mistos (MMM), desenvolvida por Henderson (1975), porém esta metodologia preconiza que a população esteja em equilíbrio de Hardy-Weinberg, ou seja, admite- se que as frequiências gênicas não se alterem de geração para geração e que o acasalamento entre os animais ocorra ao acaso (não existe seleção), considerando-se assim o coeficiente de endogamia igual a zero.

A endogamia é um sistema de acasalamento em que os indivíduos mais aparentados entre si que a média da população são utilizados como reprodutores da próxima geração (BREDA et al., 2004). De acordo com esses autores, a endogamia tem como principal efeito genético o aumento da homozigose e o aparecimento de genes recessivos que, geralmente, provocam alguma alteração na média do mérito individual. A medida do aumento da homozigose é dada pelo coeficiente de endogamia, cujo valor é zero em uma população base, ou seja, sem nenhum parentesco entre os animais. Portanto, em populações com elevados valores

\footnotetext{
'Mestrando em Estatística e Experimentação Agropecuária - Programa de Pós-Graduação e Estatística Agropecuária - Departamento de Ciências Exatas/DEX - Universidade Federal de Lavras/UFLA - Cx. P. 3037 - 37200-000 - Lavras, MG - rreis18@gmail.com

'Engenheiro Agrônomo, Doutor em Estatística e Experimentação Agronômica, Professor Titular - Departamento de Ciências Exatas/DEX - Universidade Federal de Lavras/UFLA - Cx. P. 3037 - 37200-000 - Lavras, MG - joamuniz@ufla.br

3Zootecnista, Doutor em Estatística e Experimentação Agronômica, Professor Adjunto II - Centro de Ciências Exatas e Tecnológicas - Universidade Federal de Viçosa/UFV - 36571-000 - Viçosa, MG - fabyano@dpi.ufv.br

${ }^{4}$ Engenheiro Agrônomo, Mestre em Estatística e Experimentação Agronômica - Departamento de Ciências Exatas/DEX - Universidade Federal de Lavras/UFLA - Cx. P. 3037 - 37200-000 - Lavras, MG - Ihaquino@ufla.br
} 
para esse coeficiente, tem-se perda parcial do ganho genético obtido por seleção e redução do valor fenotípico médio.

Ainda a respeito do coeficiente de endogamia, esse depende do tamanho efetivo da população e, quanto menor for o tamanho da população, em gerações anteriores, maior será o número de ancestrais comuns e maior será o coeficiente de endogamia (BREDA et al., 2004).

$\mathrm{Na}$ existência da variabilidade genética, quantificada geralmente pela variância genética aditiva, reside toda capacidade de se promover seleção, e conseqüentemente melhoramento genético (EUCLIDES FILHO, 1999). Isso porque, a variância genética aditiva é um componente do índice denominado herdabilidade, o qual nos informa a possibilidade de se utilizar a variável em questão em programas de melhoramento ou não (FONSECA, 1999). De acordo com essas informações, é possível observar a importância desse componente para o melhoramento genético.

Segundo Fries \& Schenkel (1993), os melhoristas vivem em mundos separados, visto que, embora sua mais importante ferramenta seja a seleção, a atual metodologia de modelos mistos tem como premissa que nenhuma seleção esteja ocorrendo.

Sorensen \& Kennedy (1984) e Werf \& Boer (1990), por meio de estudos de simulação, observaram que, em populações selecionadas, ocorreu redução na variância genética aditiva e aumento do coeficiente de endogamia. Braccini Neto (1999) também utilizando simulação de dados constatou que a seleção fenotípica imposta, com diferentes intensidades de seleção, causou aumento no coeficiente de endogamia e redução na variância genética aditiva.

Gianola et al. (1988) chamam a atenção para a importância de se desenvolverem métodos estatísticos que considerem o fenômeno de seleção e, alternativamente, de se estabelecerem condições sob as quais a seleção pudesse ser ignorada, de modo que o procedimento aplicável na ausência de seleção possa ser empregado.

Alguns métodos de avaliação genética são menos vulneráveis a esses efeitos de seleção do que outros, tornando-se necessário proceder a uma comparação entre eles (HENDERSON, 1985). Esse autor sugere a simulação de dados como uma alternativa para esses estudos, quando os dados de campo envolvem manipulações matemáticas difíceis que exigem muito tempo de computação.

Uma alternativa para estudos de simulação de dados, muito utilizada em recentes estudos de melhoramento genético é a técnica de Monte Carlo, que objetiva a geração de números pseudo-aleatórios segundo uma distribuição de probabilidade pela qual se tenha interesse. Esse método tem sido amplamente empregado nas mais diversas áreas da ciência, pois representa, por exemplo, a possibilidade de testar uma técnica de análise sem a necessidade de se coletarem dados reais (MORE \& TSIATIS, 1991).

Atualmente, existe uma concentração de grande número de informações de registros e acompanhamento da produção em poucos centros de pesquisas, restringindo o trabalho de muitos melhoristas que não têm acesso a esses dados. Isso acontece porque os dados de campo para pesquisas em Melhoramento Genético Animal geralmente pertencem a grandes associações de criadores, responsáveis pelos registros e acompanhamento da produção, que os utilizam para fazer a avaliação genética dos animais. A simulação de dados então aparece como uma ferramenta importante para disponibilizar material de pesquisa para suprir a carência de informações nessa área.

Quanto às bovinoculturas de leite e de corte, devido ao grande intervalo de geração, há necessidade de muito tempo para se obter dados que possam ser utilizados em pesquisas que visem comparações de metodologias, utilizando dados de sucessivas gerações em populações sob seleção. Nesse caso, a simulação de dados via método Monte Carlo figura-se como uma alternativa viável para o problema, pois além de fornecer resultados confiáveis, possibilita também uma redução de tempo e custo inerentes a pesquisas desenvolvidas nessa área (SILVA et al., 2001). Em recentes estudos de Melhoramento Genético Animal (BREDA et al., 2004; CUNHA et al., 2003) os autores também se referem à importância da simulação de dados, alegando que sua utilização permite a realização de estudos de métodos de seleção, de testes de pressuposições matemáticas e de avaliações de novas metodologias de seleção.

Os estudos de simulação de dados na área de Melhoramento Animal têm sido realizados por meio de programas desenvolvidos em linguagem FORTRAN, que demandam grande conhecimento computacional (não se trata de uma linguagem específica para estudos genéticos e estatísticos). Desse modo, a alternativa do uso do software estatístico R, para desenvolver esses estudos de simulação, que são mais compatíveis com a área de estatística e genética, surge como uma opção viável.

O software R é uma linguagem e um ambiente para computação estatística e gráficos e fornece uma ampla variedade de técnicas estatísticas (linear, não linear, testes estatísticos clássicos, análise de séries temporais, classificação, "clustering”, ...) e gráficas, e é altamente extensível. 
Objetivou-se, neste trabalho, avaliar o comportamento da variância genética aditiva de populações selecionadas e não selecionadas por seis gerações sucessivas, via simulação Monte Carlo, e disponibilizar um sistema de fornecimento de dados para pesquisas de Melhoramento Animal, por meio do software R.

\section{MATERIAL E MÉTODOS}

Para a realização do estudo foi utilizado o método de simulação descrito por Sorensen \& Kennedy (1984), e também utilizado por Pieramati \& Vleck (1993) e Werf \& Boer (1990) que consiste em, por meio da simulação Monte Carlo, gerar dados de uma população-base constituída por 40 machos e 40 fêmeas não aparentados, não selecionados e não endogâmicos, ou seja, em equilíbrio de HardyWeinberg (geração 0). Após gerar essa população, foram amostrados 5 machos e 20 fêmeas, que foram acasalados aleatoriamente, sendo cada macho acasalado com 4 fêmeas diferentes, originando-se duas progênies de cada acasalamento, um macho e uma fêmea (20 machos e 20 fêmeas ao todo), constituindo-se assim a geração 1, com um total de 40 animais, valor que se repete nas demais gerações. Para gerar a população sob seleção, os 5 machos fenotipicamente superiores (que apresentaram os maiores valores para a característica simulada) foram selecionados, sendo cada um acasalado aleatoriamente com 4 fêmeas dessa mesma geração, gerando um macho e uma fêmea por casal (20 machos e 20 fêmeas ao todo), produzindo a geração 2, sendo esse procedimento repetido até a sexta geração. A população não selecionada foi obtida, em cada geração, por meio de amostras aleatórias. Os dados da geração 0 foram simulados, a partir do seguinte modelo genético aditivo:

$$
y_{i}=\mu+a_{i}+e_{i}
$$

em que:

$y_{i}$ é o valor fenotípico do i-ésimo animal; $\mu$ é uma constante (recebeu o valor 100); $a_{i}$ é o valor genético aditivo; $e_{i}$ é o efeito ambiental aleatório (erro) da observação do i-ésimo animal.

Na geração 0 , os valores de $a_{i}$ foram gerados por meio de uma distribuição normal com média 0 e variância $\left(\sigma_{a}^{2}\right)$ 10. Nas gerações subseqüentes $(1,2,3,4,5)$ os valores de $a_{i}$ foram obtidos por meio da expressão: $a_{i}=(1 /$ 2) $\mathrm{a}_{\mathrm{si}}+(1 / 2) \mathrm{a}_{\mathrm{di}}+\Phi$, em que $\mathrm{a}_{\mathrm{si}}$ e $\mathrm{a}_{\mathrm{di}}$ são valores genéticos aditivos do pai e da mãe, respectivamente, do i-ésimo animal e $\Phi$ é o valor correspondente à segregação mendeliana, gerado com média 0 e variância $\left(\sigma_{\Phi i}^{2}\right)$ dada pela expressão: $\quad \sigma_{\Phi i}^{2}=\left[1 / 2-(1 / 4)\left(\mathrm{F}_{\mathrm{si}}+\mathrm{F}_{\mathrm{di}}\right)\right] \sigma_{a}^{2}$ onde $\mathrm{F}_{\mathrm{si}}$ e $\mathrm{F}_{\mathrm{di}}$ são os coeficientes de endogamia do pai e da mãe, respectivamente, do i-ésimo animal . Esses coeficientes foram calculados utilizando-se a função kin.morgan do pacote GAP (Genetic Analysis Package) do software estatístico R. Valores para e foram simulados por meio de uma distribuição normal com média 0 e variância $\left(\sigma_{e}^{2}\right) 10$, dessa forma a herdabilidade $\left(\mathrm{h}^{2}\right)$ inicial $\left(\mathrm{h}^{2}=\sigma_{a}^{2} / \sigma_{a}^{2}+\right.$ $\sigma_{e}^{2} ; h^{2}=10 / 10+10$ para a característica simulada foi de 0,5 .

Os valores $a_{i}$ e e foram simulados por meio da função rnorm do R, que gera uma variável aleatória com distribuição normal com média e variância de acordo com a indicada. Por exemplo, ao gerar 40 números com média zero e variância dez, ou seja, com desvio-padrão igual a 3,162278, a seguinte rotina deve ser utilizada: rnorm(40,0,3,162278). Todo o processo de simulação, descrito anteriormente, foi realizado para 1.000 repetições. A opção pelo $\mathrm{R}$ deve-se à facilidade de geração de números aleatórios, e também ao fato de ser um software atualmente muito utilizado, tornando esse método de simulação acessível para muitos pesquisadores.

As variâncias genéticas aditivas para cada geração $\left(\sigma_{a_{\mathrm{t}}}^{2}\right)$ foram calculadas de acordo com a fórmula apresentada por Werf \& Boer (1990): $\quad \sigma_{a_{t}}^{2}=1 / n-1\left(\mathbf{a}_{\mathbf{t}}{ }^{\prime} \mathbf{a}_{\mathbf{t}}-n \bar{a}_{t}^{2}\right)$, sendo $\mathbf{a}_{\mathbf{t}} \mathrm{o}$ vetor dos valores genéticos, $\mathrm{n}$ o número de animais e $\bar{a}_{t}$ a média genética aditiva a cada $t$ geração.

\section{RESULTADOS E DISCUSSÃO}

Por meio dos resultados apresentados na Tabela 1 é possível avaliar o comportamento das populações selecionadas e não selecionadas durante seis gerações sucessivas.

Observa-se pela Tabela 1 e pelas Figuras 1 e 2 que, em ambas as populações (selecionada e não selecionada), ocorre uma diminuição da variância genética aditiva $\left(\sigma_{\mathrm{a}}^{2}\right)$ e um aumento do coeficiente de endogamia $(F)$ com a seleção nas sucessivas gerações. Esses resultados estão de acordo com Braccini Neto (1999), que estudando sucessivas gerações por meio de simulação de dados observou que a seleção imposta causou redução na variância genética aditiva. Pieramati \& Vleck (1993) atribuem a similaridade das populações selecionadas e não selecionadas, quanto à redução na variância genética aditiva, ao aumento do coeficiente de endogamia e ao pequeno tamanho da população, e comentam que quanto maior a população menos evidente são esses resultados. 
Tabela 1 - Estimativas da variância genética aditiva $\left(\mathrm{s}_{\mathrm{a}}^{2}\right)$ e do coeficiente de endogamia (F) em cada geração.

\begin{tabular}{ccccc}
\hline & \multicolumn{2}{c}{$\begin{array}{c}\text { Populações } \\
\text { selecionadas }\end{array}$} & \multicolumn{2}{c}{$\begin{array}{c}\text { Populações não } \\
\text { selecionadas }\end{array}$} \\
\cline { 2 - 5 } Geração & $\mathrm{s}^{2}{ }_{\mathrm{a}}$ & $\mathrm{F}$ & $\mathrm{s}_{\mathrm{a}}{ }^{2}$ & $\mathrm{~F}$ \\
\hline 0 & 9,9989 & 0,0000 & 10,1427 & 0,0000 \\
1 & 8,6928 & 0,0000 & 9,7656 & 0,0000 \\
2 & 7,8520 & 0,0328 & 9,1243 & 0,0300 \\
3 & 7,0816 & 0,0596 & 8,7950 & 0,0569 \\
4 & 6,3289 & 0,0863 & 8,0400 & 0,0790 \\
5 & 5,5596 & 0,1158 & 7,3577 & 0,1026 \\
\hline
\end{tabular}

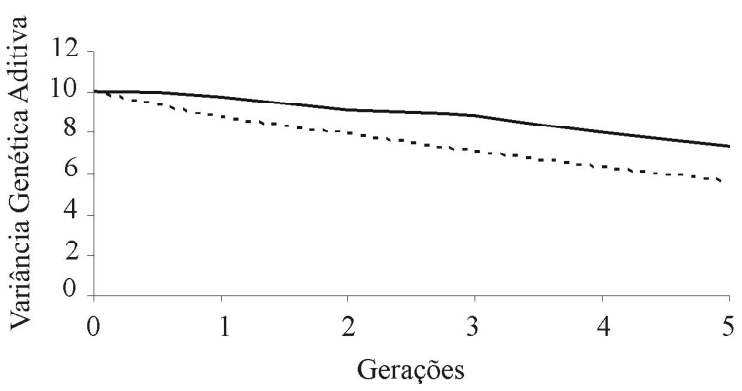

. . . . . População selecionada ——População não-selecionada

Figura 1 - Variância genética aditiva no decorrer de sucessivas gerações.

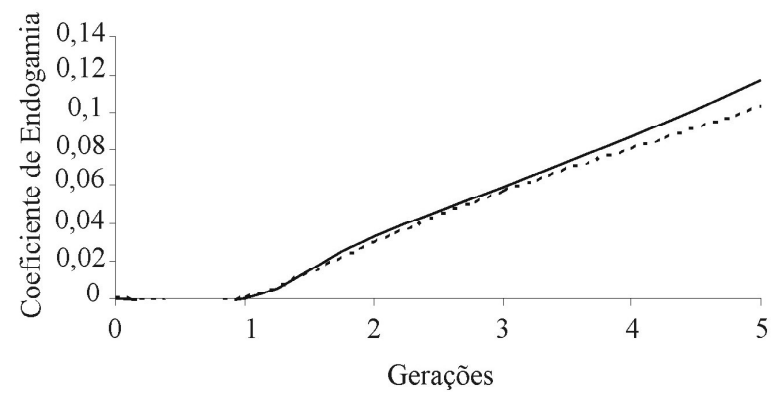

População selecionada - ..... População não-selecionada

Figura 2 - Coeficiente de Endogamia, no decorrer de sucessivas gerações.

A diminuição da $\sigma_{a}^{2}$ na população com acasalamento aleatório está relacionada principalmente com $\mathrm{o}$ aumento em $\mathrm{F}$ pois se trata de uma população de tamanho finito originada de um modelo genético aditivo. $\mathrm{Na}$ população sob seleção, esse declínio se deve, além do aumento da endogamia a mudanças direcionais nas freqüências gênicas, o que reflete o aumento da média genética dessa população. Essas informações são necessárias para o desenvolvimento de pesquisas que visem à comparação de metodologias de avaliação genética, considerando o efeito de seleção em sucessivas gerações, da geração zero até a sexta. Percebe-se pelos resultados que houve uma redução na $\sigma_{\mathrm{a}}^{2}$ de $44,4 \%$, devido a um aumento de $11,58 \%$, no coeficiente de endogamia $(\mathrm{F})$ na população selecionada. Na população não selecionada a redução na $\sigma_{a}^{2}$ foi de $27,46 \%$ devido a um aumento de $10,26 \%$ em F.

A explicação mais simples para o declínio da variância genética aditiva, de características quantitativas, provocado pela endogamia é caracterizada pelo fato de genes serem fixados, fator que diminui a variância em questão, sendo essa explicação melhor compreendida em pequenas populações (FALCONER, 1981). Na prática, isso significa que, ao longo do tempo, o rebanho pode sofrer com algum problema pelo acúmulo de genes indesejáveis, o que resulta em perda de produtividade. Além disso, também pode-se esperar uma diminuição na herdabilidade a cada geração, fato esse que pode vir representar um ponto a partir do qual a variável em estudo não mais será recomendada para o programa de seleção, uma vez que sua herdabilidade será muito baixa.

\section{CONCLUSÕES}

Em populações selecionadas a redução da variância genética aditiva ocorre devido ao aumento da endogamia.

Em populações sob acasalamento aleatório a variância genética aditiva decresce a cada geração em função do aumento da endogamia, proporcionalmente em menor intensidade em relação à população selecionada.

Os resultados obtidos, similares a outros trabalhos, em que não se utilizou o $\mathrm{R}$, indicam que o método de simulação de dados empregado foi eficiente.

\section{REFERÊNCIAS BIBLIOGRÁFICAS}

BRACCINI NETO, J. Comparação de metodologias de predição de valores genéticos utilizando simulação de dados selecionados. 1999. 73 f. Tese (Doutorado) Universidade Federal de Viçosa, Viçosa, 1999.

BREDA, F. C.; EUCLYDES, R. F.; PEREIRA, C. S. Endogamia e limite de seleção em populações selecionadas obtidas por simulação. Revista Brasileira de Zootecnia, Viçosa, v. 33, p. 2017-2025, 2004.

CUNHA, E. E.; EUCLYDES, R. F.; TORRES, R. A. Efeito de tipos de acasalamentos e razões sexuais na seleção baseada 
no BLUP. Revista Brasileira de Zootecnia, Viçosa, v. 32, p. 1297-1303, 2003.

EUCLIDES FILHO, K. Melhoramento genético animal no Brasil: fundamentos, história e importância. Campo Grande: Embrapa, 1999. 63 p.

FALCONER, D. D. Introdução à genética quantitativa. Viçosa: UFV, 1981. 279 p.

FAIRFULL, R. F.; MUIR, W. M. Quantitative genetics versus molecular genetics in poultry breeding. In: REUNIÃO ANUAL DA SOCIEDADE BRASILEIRA DE ZOOTECNIA, 34., 1997, Juiz de Fora. Anais... Juiz de Fora: SBZ, 1997. p. 52-78.

FONSECA, R. da. Efeito da violação de pressuposições da metodologia de modelos mistos na avaliação genética animal. 1999. 57 f. Dissertação (Mestrado) - Universidade Federal de Viçosa, Viçosa, 1999.

FRIES, L. A.; SCHENKEL, F. S. Estimation and prediction under a selection model. In: REUNIÃO ANUAL DA SOCIEDADE BRASILEIRA DE ZOOTECNIA, 30., 1993 , Rio de Janeiro. Anais... Rio de Janeiro: SBZ, 1993. p. 1-22.

GIANOLA, D.; IM, S.; FERNANDO, R. L. Prediction of breeding value under Henderson's selection model: a revision. Journal Dairy Science, Champaign, v. 71, n. 10, p. 2790-2798, 1988.

HENDERSON, C. R. Comparison of alternative sire evaluation methods. Journal Animal Science, Champaign, v. 41, n. 3, p. 760-770, 1975.
HENDERSON, C. R. Best linear unbiased prediction using relationship matrices derived from selected base populations. Journal Dairy Science, Champaign, v. 68, n. 2, p. 443-448, 1985.

MORE, D. F.; TSIATIS, A. Robust estimation of variance in moment methods for extra-binomial and extra-poisson variation. Biometrics, Washington, v. 47, n. 2, p. 383-401, 1991.

PIERAMATI, C.; VLECK, L. D. Effect of genetic groups on estimates of additive genetic variance. Journal Animal Science, Champaign, v. 71, n. 1, p. 66-70, 1993.

SILVA, F. F.; AQUINO, L. H.; OLIVEIRA, A. I. Estimativas de variâncias genéticas aditivas em populações selecionadas e não selecionadas via simulação Monte Carlo. In: RBRAS-SEAGRO, 2001, Piracicaba, SP. Anais... Piracicaba: ESALQ, 2001.

SORENSEN, D. A.; KENNEDY, B. W. Estimation of genetics variances from unselected and selected populations. Journal Animal Science, Champaign, v. 59, n. 5, p. 12131223, 1984.

WERF, J. H. J. van der; BOER, I. J. M. Estimation of additive genetic variance when base populations are selected. Journal Animal Science, Champaign, v. 68, n. 10, p. 31243132, 1990. 


\section{APÊNDICE: IMPLEMENTAÇÃO EM LINGUAGEM R}

Os quadros 1 e 2 representam um resumo simplificado das funções implementadas no software R. Foram implementadas duas funções, uma para populações selecionadas e outra para populações não-selecionadas.
Maiores detalhes sobre a implementação dessas funções poderão ser encontradas no site

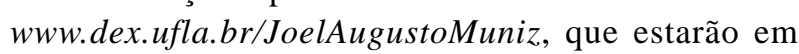
constante atualização com uma posterior implementação de uma interface gráfica.

Quadro 1 - Função implementada para Populações Não-Selecionadas.

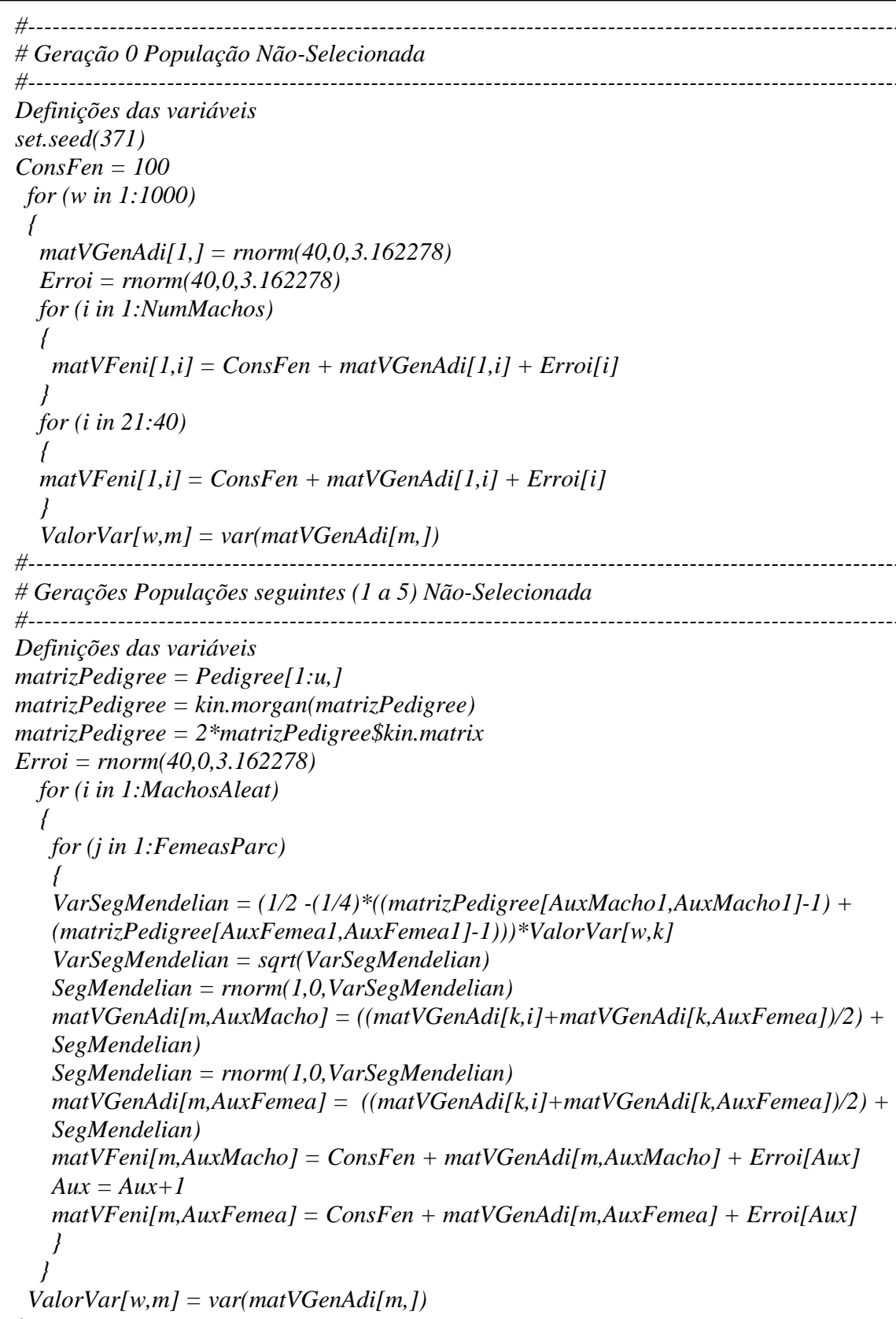

Ciênc. agrotec., Lavras, v. 33, n. 1, p. 285-291, jan./fev., 2009 
Quadro 2 - Função implementada para Populações Selecionadas.

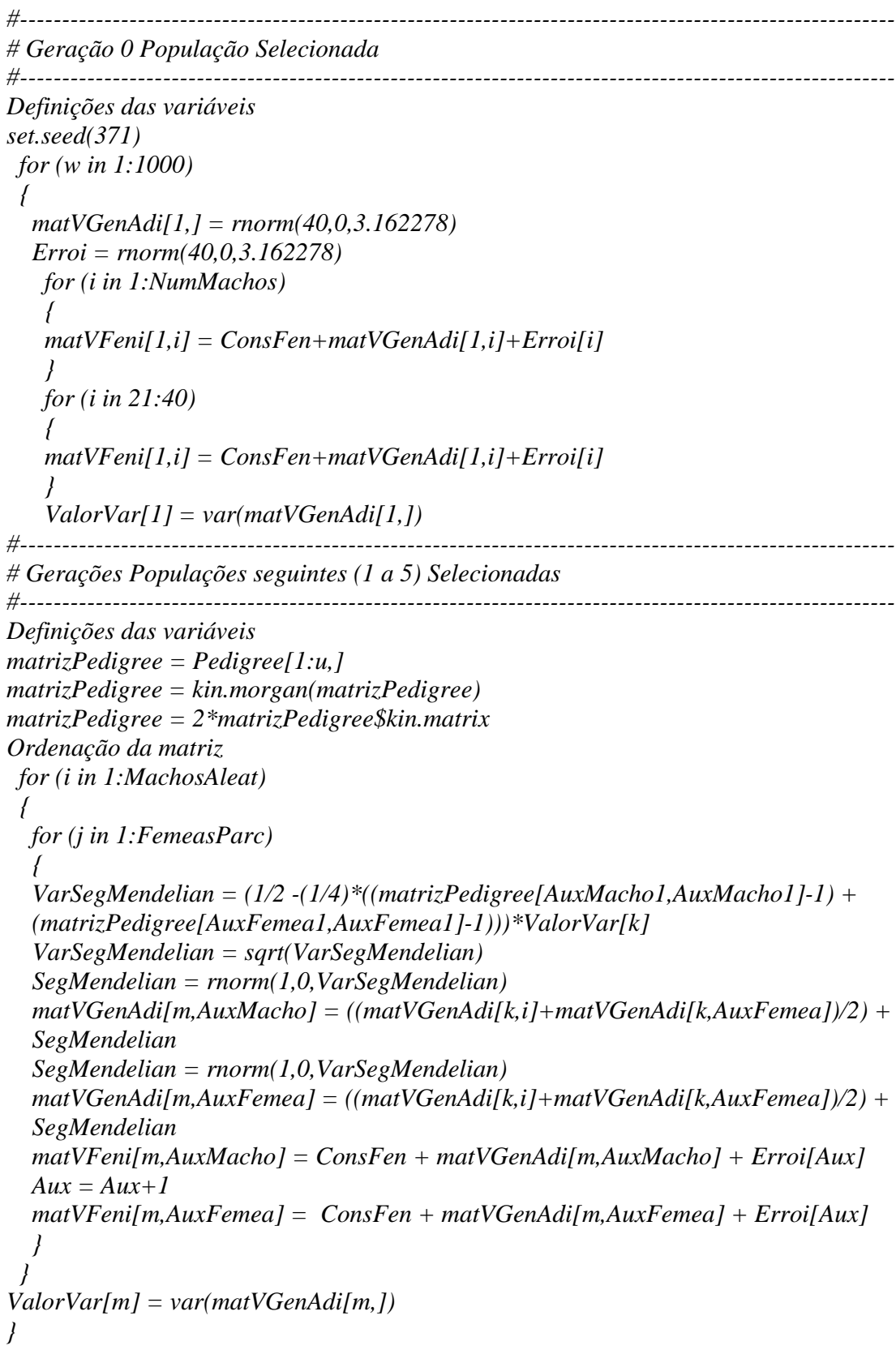

